\title{
Assessment of Snow Cover and Surface Albedo in the ECHAM5 General Circulation Model
}

\author{
ANDREAS ROESCH \\ Institute for Atmospheric and Climate Science, Swiss Federal Institute of Technology (ETH), Zurich, Switzerland \\ ERICH ROECKNER \\ Max Planck Institute for Meteorology, Hamburg, Germany
}

(Manuscript received 30 November 2004, in final form 18 August 2005)

ABSTRACT

Land surface albedo, snow cover fraction (SCF), and snow depth (SD) from two versions of the ECHAM climate model are compared to available ground-based and remote-sensed climatologies.

ECHAM5 accurately reproduces the annual cycle of SD and correctly captures the timing of the snowmelt. ECHAM4, in contrast, simulates an excessive Eurasian snow mass in spring due to a delayed snowmelt. Annual cycles of continental snow cover area (SCA) are captured fairly well in both ECHAM4 and ECHAM5. The negative SCA trend observed during the last two decades of the twentieth century is evident also in the ECHAM5 simulation but less pronounced. ECHAM5 captures the interannual variability of SCA reasonably well, which is in contrast with results that were reported earlier for second-phase Atmospheric Model Intercomparison Project (AMIP II) models. An error analysis revealed that, for studies on SCA, it is essential to test the data records for their homogeneity and trends.

The second part of the paper compares simulated surface albedos with remote-sensed climatologies derived from PINKER and the Moderate Resolution Imaging Spectroradiometer (MODIS). ECHAM5 is in better agreement with observations in the Himalayan-Tibetan area than ECHAM4. In contrast, the positive surface albedo bias over boreal forests under snow conditions in ECHAM4 is even more pronounced in ECHAM5. This deficiency is mainly due to the neglect of the snow-masking effect of stems and branches after trees have lost their foliage.

The analysis demonstrates that positive biases in the SCA are not necessarily related to positive albedo biases. Furthermore, an overestimation of the area-averaged SD is not always related to positive SCF anomalies since the relationship between SD and SCF is highly nonlinear.

\section{Introduction}

Snow cover plays a key role in the climate system as it largely affects both the energy balance, through the high reflectivity of snow, as well as regional water budgets, and thus evaporation and the hydrological cycle. Snow depth exhibits a strong annual cycle with a distinct interannual variability at midlatitudes. Over $50 \%$ of Eurasia and North America can be seasonally covered by snow (Robinson et al. 1993). Numerous studies have shown the importance of snow for weather fore-

Corresponding author address: Andreas Roesch, Institute for Atmospheric and Climate Science, Swiss Federal Institute of Technology (ETH), Winterthurerstr. 190, CH-8057 Zurich, Switzerland.

E-mail: andreas.roesch@env.ethz.ch casts as well as for climate simulations from local to global scale. Barnett et al. (1989) confirmed the sensitivity of the Indian monsoon to the Eurasian snow cover. Walsh and Ross (1988) tested the sensitivity of 30-day forecasts to continental snow cover and found large sensitivity over Eurasia. Snow cover is related to many feedbacks (Randall et al. 1994), the most obvious being the snow-albedo feedback: A positive temperature perturbation leads to more snowmelt and favors rain over snowfall, which leads to a decrease of surface albedo. This allows larger absorption of solar radiation, which reinforces further warming. Snow is a very useful diagnostic parameter since, in order to correctly model snow thickness, both the temperature and precipitation distribution need to be realistic.

Snow also acts as a water storage reservoir, which is released during snowmelt in spring. Thus, snow cover 
largely influences runoff, soil moisture, evaporation, and, therefore, precipitation and the entire hydrological cycle, as reported in many studies (e.g., Douville et al. 2002; Groisman et al. 2004).

In climate models, snow cover fraction (SCF) is diagnostically derived from the snow water equivalent (SWE), which is a prognostic variable in most models. A correct simulation of the SCF is crucial for the computation of surface albedo during the winter season, and the literature presents several parameterizations for use in GCMs (Dickinson et al. 1993; Marshall et al. 1994; Sellers et al. 1996; Yang et al. 1997; Roesch et al. 2001).

Surface albedo is closely related to snow cover as a large part of its interannual variability is caused by changes in the snow cover area (SCA). It is thus reasonable to discuss surface albedo and snow cover together. However, surface albedo is also subject to large variability in snow-free areas since the albedo also depends on the soil wetness of the uppermost soil layer (Culf et al. 1995), the solar angle (Verseghy et al. 1993), the solar spectrum (Briegleb and Ramanathan 1982), and modifications in the type of the vegetation cover (e.g., through deforestation, overgrazing). As for snow, the effect of varying surface albedo on the surface climate may be further enhanced through positive feedbacks such as the vegetation feedback (Claussen 1997). Numerous studies have shown that climate models exhibit a significant sensitivity to surface albedo changes (Charney et al. 1977; Potter et al. 1981; HendersonSellers and Wilson 1983; Roesch et al. 2002).

This paper deals with the validation of the surface albedo and snow cover in two versions of the ECHAM model and is organized as follows. In section 2, the model and the experimental design are described. Section 3 deals with the observed data used in this analysis. In section 4, the simulated SWE and SCA are compared to observed snow cover data over Northern Hemisphere land areas with focus on annual cycles, interannual variability, and trends. This section includes also a thorough error analysis. In section 5, the surface albedo in both ECHAM4 and ECHAM5 are validated against remote-sensed climatologies, and deficiencies in the land surface albedo parameterization in ECHAM5 are addressed. Conclusions are drawn in section 6.

\section{Model and experimental design}

\section{a. ECHAM5}

The latest version of the Max Planck Institute GCM, ECHAM5, is described in detail in Roeckner et al. (2003). The processes that have been modified com- pared to the previous version ECHAM4 are briefly presented below. The description is limited to modifications that are relevant for the understanding of this study. A detailed description of ECHAM4 can be found in both Roeckner et al. (1992) and Roeckner et al. (1996).

Over snow-covered land, the grid-mean albedo depends on a number of parameters, such as the forest fraction, leaf area index (LAI), background albedo, (pure) snow albedo, and snow cover fraction of both the ground and the canopy (Roesch et al. 2001). The SCF is estimated differently for forests and nonforested areas.

Snow cover fraction at the ground $f_{\mathrm{sg}}$ is a function of SWE and the slope of terrain approximated by the subgrid-scale standard deviation $\sigma_{z}$ :

$$
f_{\mathrm{sg}}=0.95 \tanh (100 \mathrm{SWE})\left(\frac{1000 \mathrm{SWE}}{1000 \mathrm{SWE}+\epsilon+0.15 \sigma_{z}}\right)^{1 / 2},
$$

where $\epsilon$ is a small number used to avoid division by zero for totally flat and snow-free grid cells.

The total forest albedo $\alpha_{\text {for }}$ is computed as the sum of the closed canopy albedo $\alpha_{\text {can }}$ and ground albedo underneath the canopy $\alpha_{g}$, weighted with the fraction of closed canopy and sky view factor (SVF), respectively:

$$
\alpha_{\text {for }}=\mathrm{SVF} \alpha_{g}+(1-\mathrm{SVF}) \alpha_{\text {can }} .
$$

The SVF describes the degree of canopy closure. It is defined as the fraction of sky that the ground underlying the canopy sees and has been determined by an exponential function of the LAI,

$$
\mathrm{SVF}=e^{-\mathrm{LAI}}
$$

for both needleleaf and broadleaf trees.

The ground albedo $\alpha_{g}$ is computed as

$$
\alpha_{g}=f_{\mathrm{sg}} \alpha_{\mathrm{sg}}+\left(1-f_{\mathrm{sg}}\right) \alpha_{\mathrm{bg}},
$$

where $\alpha_{\mathrm{bg}}$ is the background albedo as estimated from Hagemann (2002). The (pure) snow albedo $\alpha_{\text {sg }}$ is parameterized as in ECHAM4, with a reduction of the melting snow albedo from 0.4 in ECHAM4 to 0.3 in ECHAM5.

The canopy albedo $\alpha_{\text {can }}$ is calculated as the sum of the snow-free canopy albedo and the albedo of the snow-covered part of the canopy $\alpha_{\text {snc }}$, weighted with their respective fractions. The snow-free canopy albedo is assumed to be equal to the snow-free background albedo $\alpha_{\mathrm{bg} \text { : }}$

$$
\alpha_{\mathrm{can}}=f_{\mathrm{snc}} \alpha_{\mathrm{snc}}+\left(1-f_{\mathrm{snc}}\right) \alpha_{\mathrm{bg}},
$$


where the fractional snow cover of the canopy $f_{\text {snc }}$ is defined as

$$
f_{\mathrm{snc}}=S_{\mathrm{nc}} / S_{\mathrm{nc}, \max },
$$

where $S_{\text {nc }}$ is the snow water equivalent at the canopy, and $S_{\text {nc,max }}$ is the maximum interception capacity, which is estimated by the product of $\left(a_{1}\right) \mathrm{LAI}$, where $a_{1}=0.2$ $\mathrm{mm}$. The intercepted snow amount is obtained from a prognostic equation including interception of snowfall, sublimation, melting, and unloading triggered by wind and temperatures close to the freezing point (Roesch et al. 2001).

Finally, the total grid-mean albedo is given by

$$
\alpha_{\text {surf }}=f_{\text {for }} \alpha_{\text {for }}+\left(1-f_{\text {for }}\right) \alpha_{g},
$$

where $f_{\text {for }}$ is the forest fraction.

Further, improved surface data are used in ECHAM5. These new global land surface data were recompiled from a global 1-km-resolution dataset (Hagemann 2002) and include background surface albedo, LAI, forest ratio, and vegetation ratio.

\section{b. Experimental design}

ECHAM5: The present-day climate was simulated by forcing the model at T106 resolution (31 vertical levels) with monthly sea surface temperatures (SSTs) and sea ice coverage for the time period 1979-99 according to the second phase of the Atmospheric Model Intercomparison Project (AMIP II).

ECHAM4: The present-day climate was simulated in a 10-yr control simulation at T106 resolution (19 vertical levels) driven by a climatological annual cycle of SST and sea ice distribution from AMIP I for the time period 1979-88 (Gates 1992).

\section{Data}

\section{a. Snow cover}

\section{1) NOAA VISIBLE DATA}

Since 1966, the National Oceanic and Atmospheric Administration (NOAA) has prepared weekly snow charts for the Northern Hemisphere. NOAA charts are based on a visual interpretation of photographic copies of visible satellite imagery by trained meteorologists. The data are given on a regular $1^{\circ} \times 1^{\circ}$ grid (Robinson 1993). In general, the NOAA charts are considered to be the most accurate means of obtaining snow cover information on large regional to hemispheric scales. Furthermore, they comprise the longest satellite-based record available and have been intensively used in former studies (Gutzler and Rosen 1992; Iwasaki 1991;
Kukla and Robinson 1981; Masuda et al. 1993; Robinson et al. 1993).

The principal shortcomings in using visible satellite imagery to chart snow cover are (i) the inability to detect snow cover when solar radiation is absent, (ii) difficulties in discriminating snow from clouds, (iii) the underestimation of snow cover where dense forests mask the underlying snow, and (iv) subgrid resolution of snow features (e.g., in areas of steep terrain). Moreover, problems arise when the snow cover is unstable or rapid changes occur. However, at a monthly resolution, data are suitable for climatic studies (Wiesnet et al. 1987).

Data that are used in this study span the time period from 1979 to 2001 and are provided at a regular $1^{\circ}$ grid. Data prior to 1979 has been omitted due to inhomogeneities in the time series caused by different satellite generations [cf. section $4 c(2)$ ].

\section{2) SSM/I MICROWAVE DATA}

Microwave-frequency data acquired from the Defense Meteorological Satellite Program (DMSP) Special Sensor Microwave Imager (SSM/I) since July 1987 have been used to estimate snow cover. The SSM/I is a seven-channel passive microwave radiometer operating at four frequencies $(19.35,22.235,37.0$, and $85.5 \mathrm{GHz})$. A thorough discussion and intercomparison of the sensors can be found in Colton and Poe (1999). The algorithm to estimate snow cover was developed by Chang et al. (1987). This algorithm uses the difference between the $37-$ and $19-\mathrm{GHz}$ channels to derive a snow depth-brightness temperature relationship for a uniform snow field. Data are provided for the period 198798 at a regular $1^{\circ}$ grid.

\section{3) MODIS MONTHLY SNOW COVER FRACTION} PRODUCT

In this analysis, a preliminary version of the gridded global monthly snow cover product MOD10CM at $0.05^{\circ}$ resolution from March 2000 to present is used. The most challenging task of compiling monthly files is the correct handling of missing values in the daily product MOD10 Level 2 from which the monthly values are derived. A final version of gridded Moderate Resolution Imaging Spectroradiometer (MODIS) snow cover fraction cannot be expected before early 2008 (D. Hall, NASA, 2004, personal communication).

\section{4) USAF/ETAC SNOW DEPTH CLIMATOLOGY}

For the validation of simulated SD, the global SD climatology of the U.S. Air Force Environmental Tech- 
nical Application Center (USAF/ETAC) as documented in Foster and Davy (1988) is used. This dataset provides a midmonthly mean SD climatology with the highest spatial resolution currently available $\left(1^{\circ} \times 1^{\circ}\right.$ equal-angle grid), using a comprehensive set of station data for the months of September to June. The USAF data are generally considered to constitute one of the most reliable and accurate snow depth climatologies available (Douville et al. 1995) and are used in several studies for the validation of snow models (Douville et al. 1995; Marshall et al. 1994; Foster et al. 1996).

\section{b. Albedo}

\section{1) MODIS}

The MODIS Bidirectional Reflectance Distribution Function (BRDF)/Albedo product is generated with data acquired by the Moderate Resolution Imaging Spectroradiometer on the Terra satellite platform. The MODIS BRDF/Albedo Product MOD43B provides both diffuse "white-sky" albedo (WSA, bihemispherical reflectance) and direct beam "black-sky" albedo (BSA, directional hemispherical reflectance at local solar noon) for seven spectral bands and three broadbands at $0.05^{\circ}$ resolution (Schaaf et al. 2002). Data used within this study are based on version V003 data, which are available from November 2000 to January 2002 with a gap in June 2001 due to instrument problems. For model comparisons, the $0.05^{\circ}$ product was aggregated to the T106 grid compatible to the resolution in the model simulations using area weighting.

\section{2) PINKER}

The PINKER surface albedo climatology has been compiled from version 2.1 of the surface albedo algorithm developed at the University of Maryland (Pinker 1985; Pinker and Laszlo 1992). Inputs are based on the International Satellite Cloud Climatology Project (ISCCP) data D1 for July 1983-December 1998 at 2.5 resolution, as provided by the Goddard Institute for Space Studies (GISS).

\section{c. Methodology}

The ECHAM models provide SWE as a prognostic output variable. From this, SCF has been diagnostically derived using Eq. (1). SCA is then computed by summing the product of each grid cell's area and the respective SCF over all cells within the region of interest.

To compare observed SD with ECHAM, simulated SWE was transformed to SD by using the density of snow $\rho_{s}$ following Verseghy (1991):

$$
\rho_{s}=\left(b_{1}+b_{2}\right) E \leq 450 \mathrm{~kg} \mathrm{~m}^{-3},
$$

where $b_{1}=188.82 \mathrm{~kg} \mathrm{~m}^{-3}$ and $b_{2}=419.0 \mathrm{~kg} \mathrm{~m}^{-2}$. This relationship accounts for mechanical compaction but ignores temperature-induced metamorphism, which might lead to significant density changes to the end of the snow season. Therefore, Eq. (8) probably underestimates snow density in spring since the snow density increases as the snowpack melts. However, the above relationship is reasonably well confirmed by using observed values of SD and SWE at six Russian sites from 1978 to 1983 (Robock et al. 1995; Roesch 2000).

To facilitate a correct comparison, all data given at grids other than T106 have been converted to T106 resolution using area weighting. ECHAM5 simulates separate SWE values for land and lake cells. As satellite-based observations of SCF do not distinguish between snow on land or lakes, SWE from both land and lake grid boxes are included in the following analysis. Both Eurasia and North America are restricted to areas north of $20^{\circ} \mathrm{N}$. Greenland and the Canadian Archipelago are excluded from the North American calculations, as is the Himalayan-Tibetan area from the Eurasian continent. The domain of Europe is restricted by the $35^{\circ} \mathrm{E}$ meridian and includes Great Britain.

\section{Results and discussion: Snow cover}

Snow cover can be characterized by either SWE or SCA. SWE plays a crucial role in the hydrologycal cycle, while SCA strongly affects the surface energy balance through the high reflectivity of snow. It is thus important to investigate the models' performance with respect to both SWE and SCA. In the following discussion, snow mass is used synonymously with SWE or SD as they are directly linked through Eq. (8).

\section{a. Snow depth}

\section{1) Annual cycle}

Snow depths of both ECHAM4 and ECHAM5 are compared with ground-based data compiled by USAF/ ETAC (cf. section 3a). Snow depth in the models has been calculated from SWE by using Eq. (8). Passive microwave data also allow the computation of snow mass. However, current algorithms tend to systematically underestimate snow mass and are not transferable between different geographic regions (Armstrong and Brodzik 2002). Therefore, such data are not used in this analysis.

The observed Eurasian SD peaks in February (Fig. 1a) and reaches its minimum in August, whereas maximum SD in North America is reached in March (Fig. 1b). ECHAM5 very accurately reproduces the annual cycles of SD in North America and in the $40^{\circ}-60^{\circ} \mathrm{N}$ 

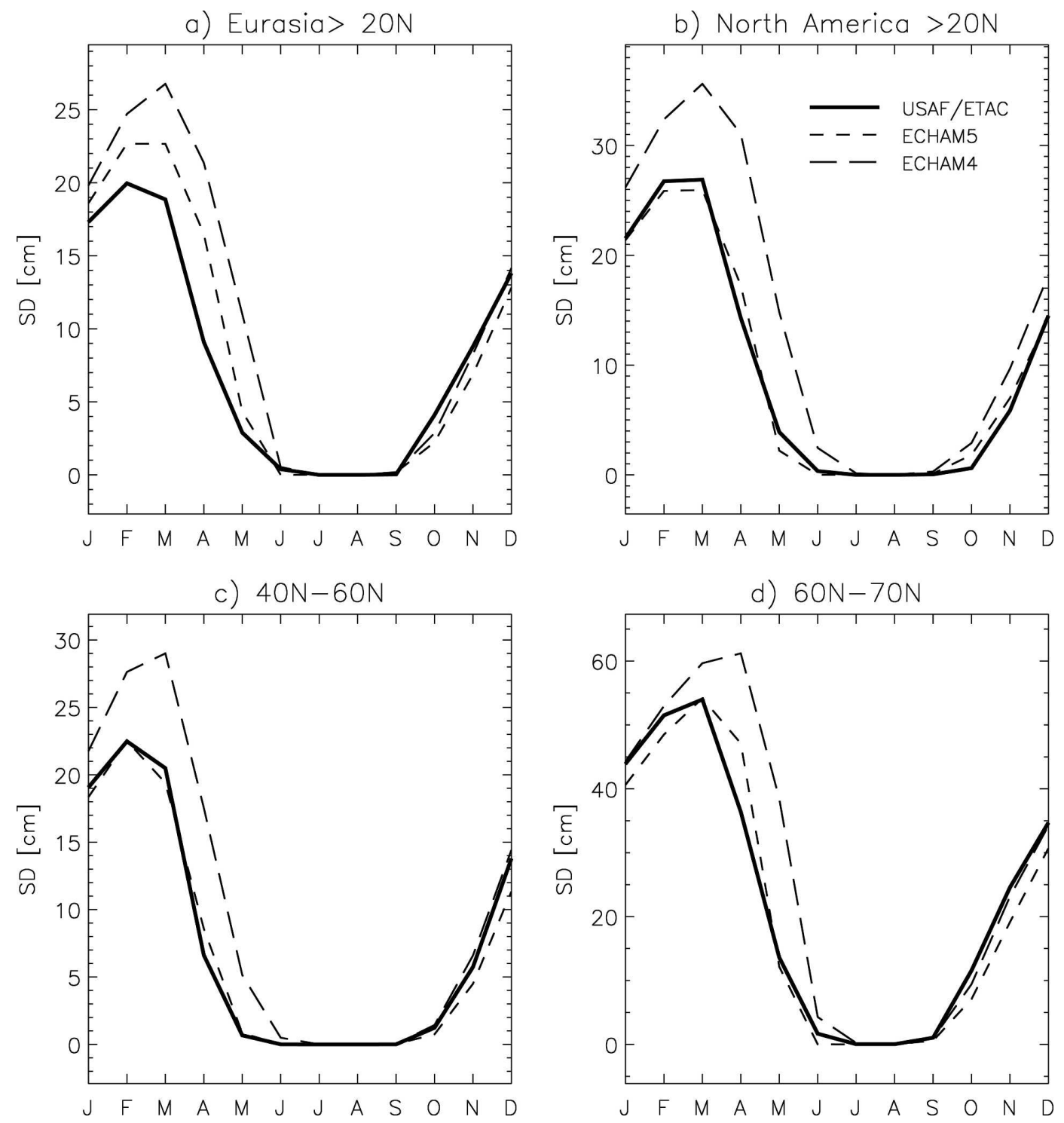

FIG. 1. Observed and simulated annual cycles of SD for (a) Eurasia $\left(>20^{\circ} \mathrm{N}\right.$, excluding the Himalayas), (b)

North America $\left(>20^{\circ} \mathrm{N}\right)$, (c) land areas $40^{\circ}-60^{\circ} \mathrm{N}$, and (d) land areas $60^{\circ}-70^{\circ} \mathrm{N}$.

latitude band. Over Eurasia SD is somewhat overestimated in late winter and spring and slightly underestimated in autumn and early winter (Fig. 1a).

ECHAM4, in contrast, substantially overestimates $\mathrm{SD}$ in all regions shown in the figure. These positive anomalies are most pronounced in late winter and spring. The highest positive biases are found in April, with 12.3 and $16.8 \mathrm{~cm}$ in Eurasia and North America, respectively, corresponding to relative errors of more than $100 \%$. As Eq. (8) probably underestimates snow density toward the end of the snow season, the detected positive SD biases might be somewhat too high. Thus, it might be problematic to specify accurate percentage differences. However, the overall results remain quantitatively correct.

The peak SD in ECHAM4 is clearly delayed. Excessive snow amount in spring is not only found in ECHAM4 but is also inherent in many other GCMs (Foster et al. 1996). In autumn and early winter, on the other hand, the observed SD is reasonably well reproduced in ECHAM4. The reason for the more realistic SD pattern in ECHAM5 may be related-among other improvements in the latest model version-to an improved representation of the snowmelt process. In ECHAM5, snowmelt is initialized when the temperature of the snow deck reaches the melting point, 
whereas in ECHAM4, both the temperature of the uppermost soil layer and the snow deck have to be heated up to $0^{\circ} \mathrm{C}$ before snowmelt occurs.

The positive SD bias is, if at all, only slightly related to incorrect precipitation rates. This is shown by comparing simulated precipitation against the precipitation from the Global Precipitation Climatology Project (GPCP), which provides area-averaged and timeintegrated monthly precipitation based on all suitable observations (Huffman et al. 1997). This global analysis contains precipitation estimates on a $2.5^{\circ} \times 2.5^{\circ}$ mesh and is based on conventional and satellite measurements.

In summary, ECHAM5 accurately portrays amplitude and phase of the annual SD cycle, whereas the previous version, ECHAM4, suffers from excessive snow depth mainly in late winter and spring.

\section{2) FREQUENCY DISTRIBUTION}

The frequency distribution of observed and simulated SD is shown in Figs. 2a,c,e,g for spring and Figs. 2b,d,f,h for autumn. Spring SDs exceeding 40 and $50 \mathrm{~cm}$ in Eurasia and North America, respectively, are far too frequent in ECHAM4 (Figs. 2a,c), while ECHAM5 reproduces these frequencies quite well. Snow depths below the above given limits occur too rarely in both ECHAM4 and ECHAM5, with the latter being slightly better compared to the observed climatology. Figure 2e reveals that the distribution of the SD between $40^{\circ}$ and $60^{\circ} \mathrm{N}$ is captured very well in ECHAM5, whereas in ECHAM4, SD is again clearly biased to high SDs. In ECHAM5 and the USAF climatology, approximately $10 \%$ of the grid cells have SDs above $30 \mathrm{~cm}$, whereas in ECHAM4, more than $20 \%$ of all grid cells in the $40^{\circ}-$ $60^{\circ} \mathrm{N}$ land belt are above this value. Excessive spring SDs in ECHAM4 are also found between $60^{\circ}$ and $70^{\circ} \mathrm{N}$. Half of all the grid cells are covered with an SD above $50 \mathrm{~cm}$ in ECHAM4, while the corresponding values in ECHAM5 (30\%) and the USAF climatology (25\%) are distinctly lower. Displaying the geographical SD pattern demonstrates that the snow line clearly protrudes too far south in ECHAM4. Excessive SD is found in both model versions in the Himalayas (not shown). However, uncertainties in SD measurements in high mountainous areas may be afflicted with significant errors and tend to underestimate the area-averaged SD because measurements are sparse and biased to lowersituated regions (valleys). Furthermore, ECHAM5 produces a significant positive precipitation bias over the southern part of the Himalayas (Hagemann et al. 2006). It can be stated, in summary, that in ECHAM5, spring $\mathrm{SD}$ is only slightly overestimated. In contrast, excessive
SD is found for ECHAM4 over the entirety of northern Eurasia and North America in spring.

In autumn, both ECHAM4 and ECHAM5 slightly underestimate the snow depth. This could be related to either an underestimation of solid precipitation or overly high temperatures or both. Comparisons of simulated surface air temperatures with the Climate Research Unit (CRU) temperature climatology (New et al. 2000) actually show a warm bias over extended parts of northern Eurasia, excluding Scandinavia, in both ECHAM4 and ECHAM5.

The comparison between the simulated precipitation and the GPCP climatology reveals that ECHAM5 slightly underestimates precipitation in autumn over parts of northern Eurasia, excluding Scandinavia and eastern Siberia (not shown).

\section{b. Snow cover area}

\section{1) AnNuAl CYCLE}

To detect the predominant discrepancies between simulated and observed snow cover, simulated annual SCA cycles at hemispheric, continental, and regional scales are compared with both visible and microwave remote-sensed observations.

The annual cycle of observed and simulated SCA over four different domains is displayed in Fig. 3. The selected areas span a total of $75.2 \times 10^{6} \mathrm{~km}^{2}$ (Northern Hemisphere), $47.2 \times 10^{6} \mathrm{~km}^{2}$ (Eurasia), $19.1 \times 10^{6} \mathrm{~km}^{2}$ (North America), and $6.5 \times 10^{6} \mathrm{~km}^{2}$ (Europe). According to the NOAA data, approximately 59\%, 60\%, 70\%, and $54 \%$ of the total area are snow-covered during the midwinter months in the Northern Hemisphere, Eurasia, North America, and Europe, respectively. Estimates from the other two remote-sensed climatologies and the models are 5\%-10\% lower. In general, NOAA provides the highest SCA for all seasons and regions, whereas ECHAM5 simulates the lowest. The ECHAM4 values are always higher than those in ECHAM5 and more in line with observations. Compared to the satellite-derived SCA climatologies, ECHAM5 tends to systematically underestimate the SCA in both Eurasia and North America. The underestimation in North America seems to be somewhat more pronounced than that over Eurasia. Note that apparently conflicting results are found: SCA is underestimated, although SD is well in line with observations. This might be due to several factors. First, positive biases in snow depth need not be related to positive biases in the SCA. SCF is only strongly sensitive to changes in SD in regions with shallow snowpacks, while changes in SD barely affect SCF when SD is relatively large. Second, SCF from visible satellite imagery only 
a) Eurasia $>20 \mathrm{~N}$, MAM

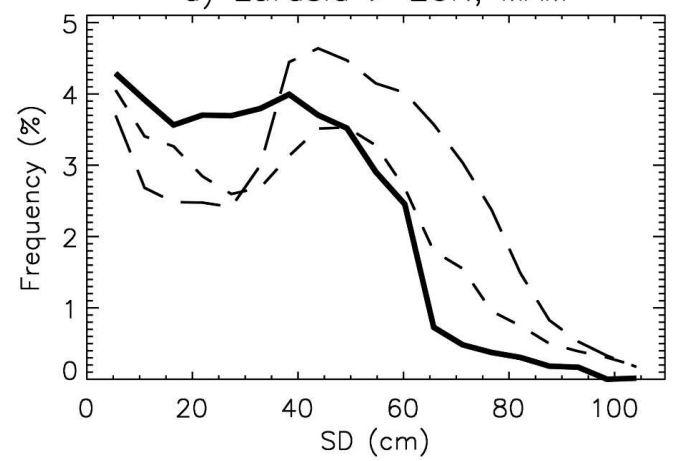

c) North America $>20 \mathrm{~N}$, MAM

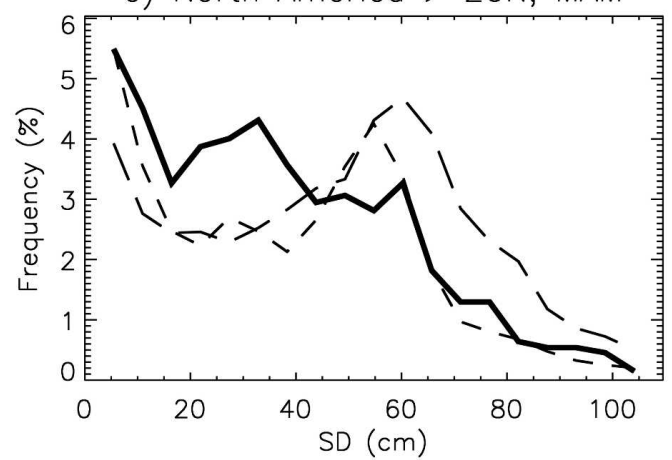

e) $40 \mathrm{~N}-60 \mathrm{~N}, \mathrm{MAM}$

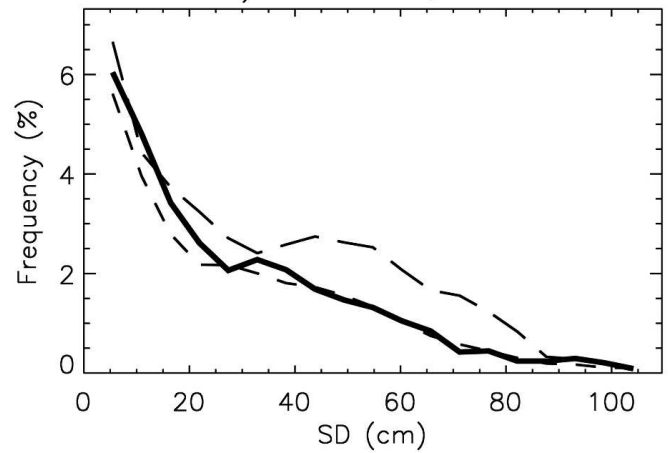

g) $60 \mathrm{~N}-70 \mathrm{~N}, \mathrm{MAM}$

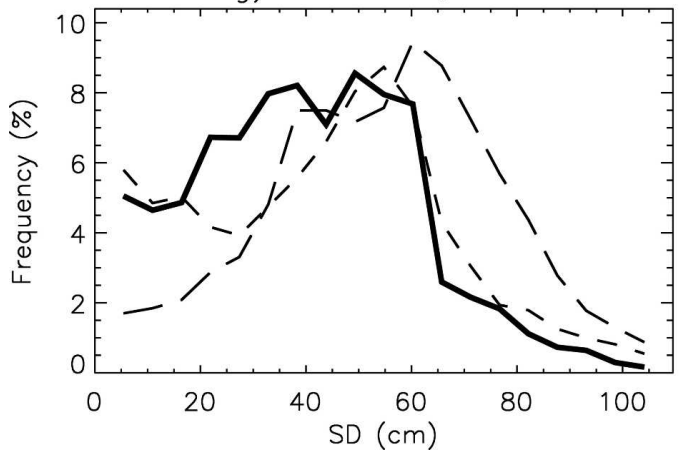

b) Eurasia $>20 \mathrm{~N}$, ON

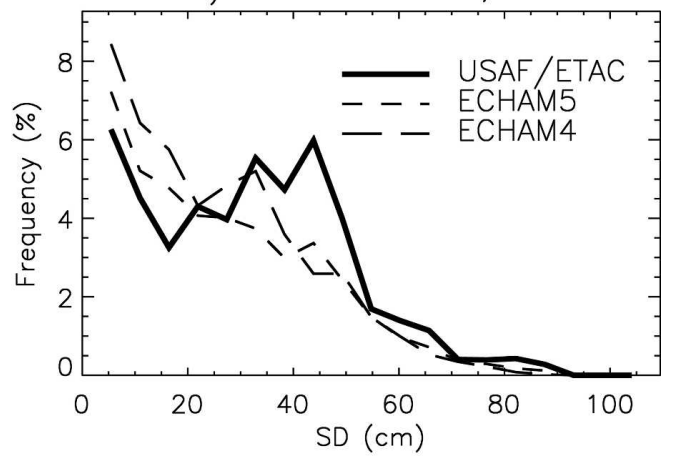

d) North America $>20 \mathrm{~N}$, ON

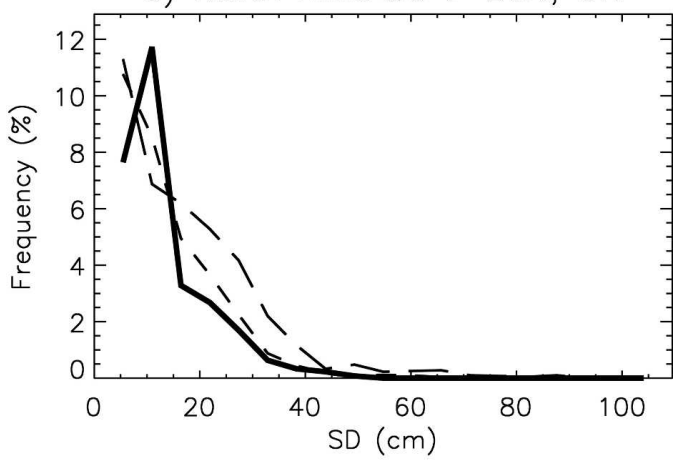

f) $40 \mathrm{~N}-60 \mathrm{~N}, \mathrm{ON}$

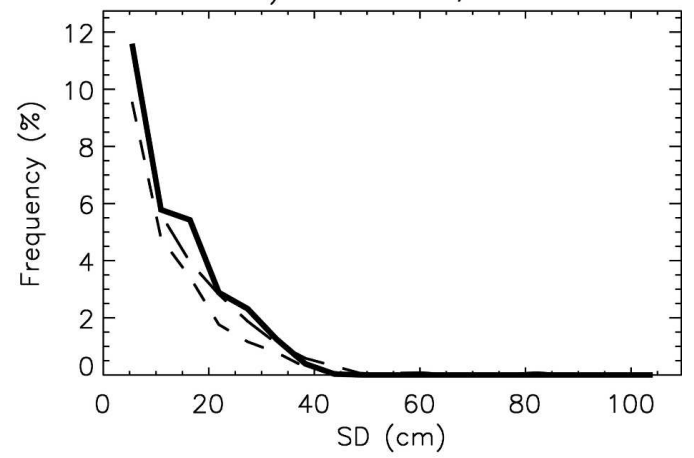

h) $60 \mathrm{~N}-70 \mathrm{~N}, \mathrm{ON}$

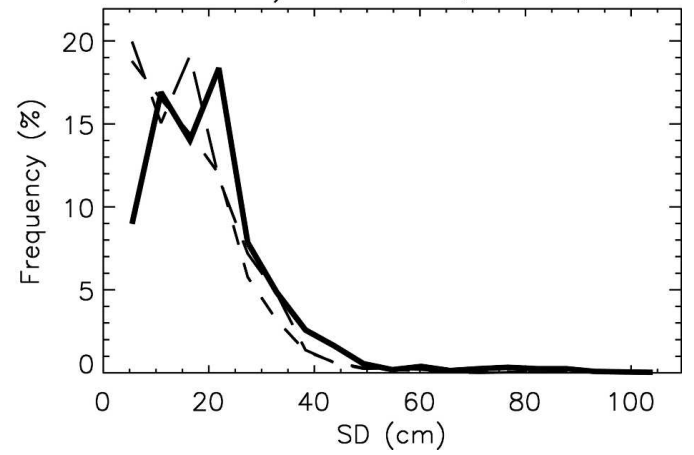

FIG. 2. Frequency distribution of SD in ECHAM4, ECHAM5, and USAF/ETAC for (a), (b) Eurasia, (c), (d) North America, (e), (f) $40^{\circ}-60^{\circ} \mathrm{N}$, and (g), (h) $60^{\circ}-70^{\circ} \mathrm{N}$. (left) March-May (MAM), (right) October-November $(\mathrm{ON})$. Class interval is $5 \mathrm{~cm}$. Frequency for class limits 0 and $5 \mathrm{~cm}$ is not shown. 
a) $\mathrm{NH}$, land, without Greenland [>20N]
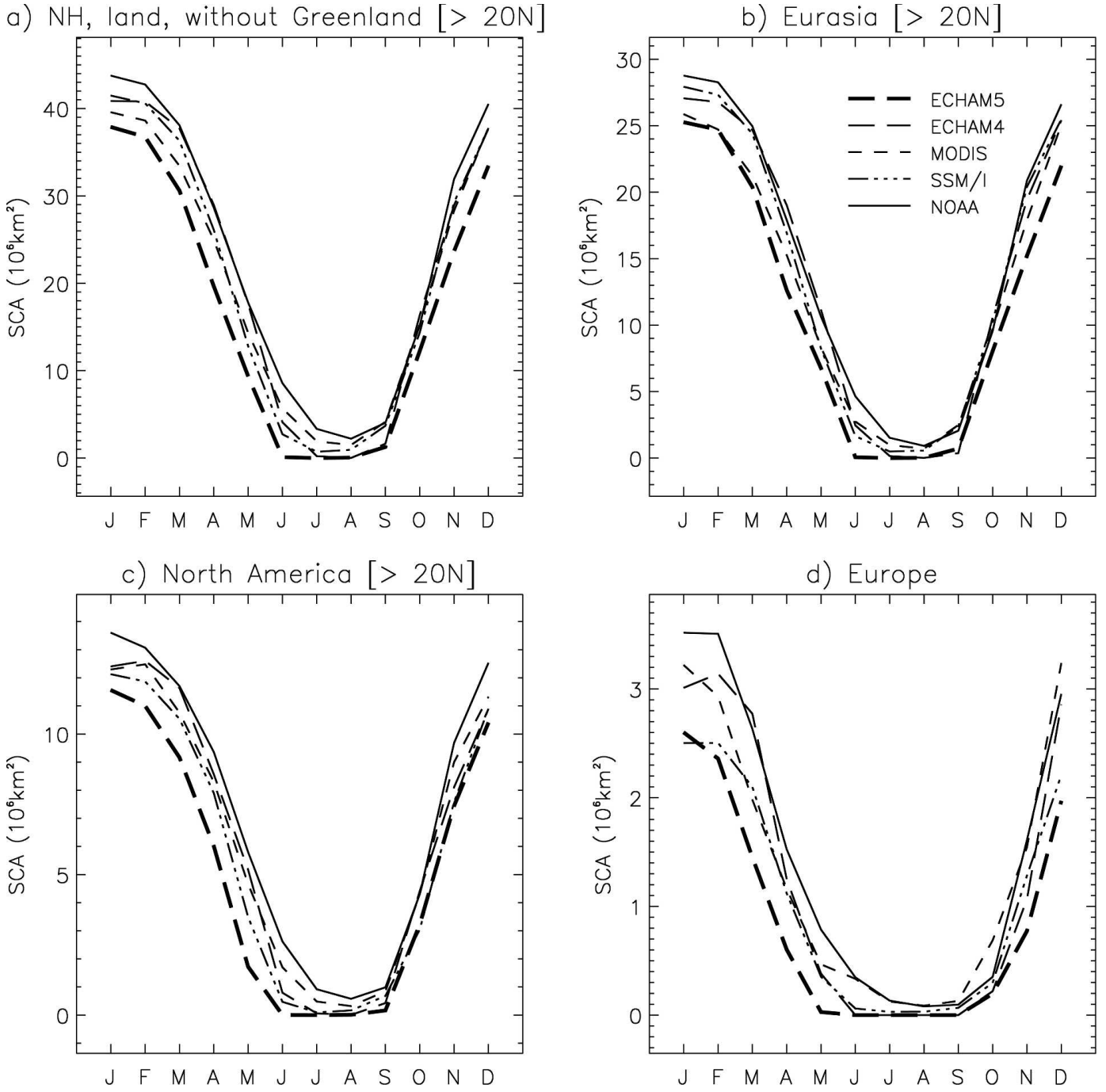

FIG. 3. Annual cycles of SCA for the (a) Northern Hemisphere (excluding Greenland), (b) Eurasia $\left(>20^{\circ} \mathrm{N}\right)$, (c) North America $\left(>20^{\circ} \mathrm{N}\right)$, and (d) Europe $\left(<35^{\circ} \mathrm{E}\right)$ for ECHAM4, ECHAM5, and NOAA, SSM/I, and MODIS (cf. section 3a). (SCA units: $10^{6} \mathrm{~km}^{2}$.) Total area of the domains $\left(10^{6} \mathrm{~km}^{2}\right)$ are $75.2,47.6,19.1$, and 6.5 for Northern Hemisphere land, Eurasia, North America, and Europe, respectively.

contains information about the existence or nonexistence of snow cover. Kukla and Robinson (1981) and Frei et al. (2003) suggest that visible satellites can detect snow over open areas for $\mathrm{SD}>2.5 \mathrm{~cm}$. This means that $\mathrm{SCF}$ equal to 1 is assumed for $\mathrm{SD}>2.5 \mathrm{~cm}$, which obviously leads to systematically higher SCFs when Eq. (1) is applied (cf. AMIP II versus ECHAM5 in Fig. 4). Figure 4 demonstrates that the simulated SCFs, for a given $\mathrm{SD}$, depend crucially on the algorithm chosen for converting SD (or SWE) into SCF. Finally, in the NOAA data, cloud contamination might cause problems in areas covered frequently with clouds. Thus, SCA differences between models and observations should not be overinterpreted. Taking into account the above-mentioned uncertainties in satellite-derived
SCAs and in the SCA algorithms employed in the models, both ECHAM4 and ECHAM5 are in reasonable agreement with the observations.

\section{2) INTERANNUAL VARIABILITY}

Besides the annual cycles and mean values it is crucial for an overall good performance of a GCM to correctly capture the interannual variability. High year-toyear variability is usually found in regions with thin snow decks, where frequent melt is observed. In contrast, SCF variations in areas with thick snowpacks are generally low, and the SCF remains close or equal to one.

Figure 5 shows the interannual variability of monthly 


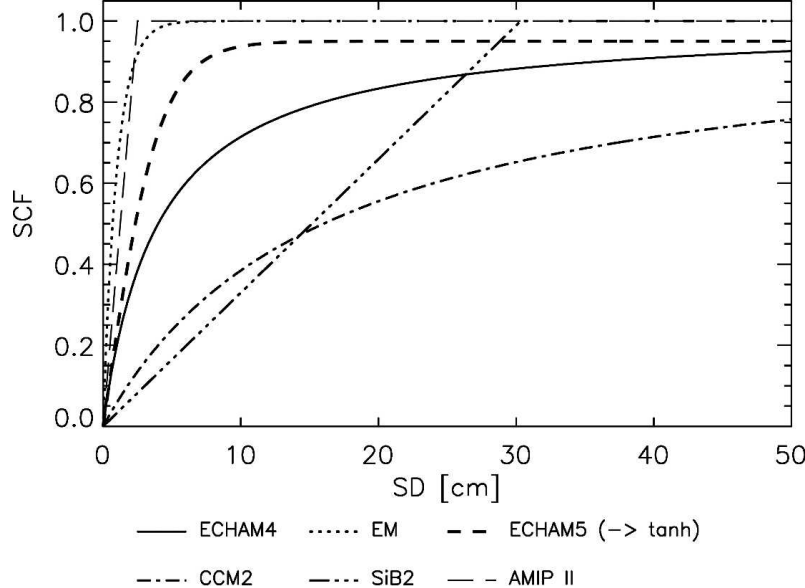

FIG. 4. SCF parameterizations used within some GCMs and land surface models. EM: Europa-Modell (Edelmann et al. 1995); CCM2: NCAR Community Climate Model (Dickinson et al. 1993); SiB2: Simple Biosphere Model (Sellers et al. 1996); AMIP II (Frei et al. 2003).

SCAs for ECHAM5 as well as for remote-sensed NOAA and SSM/I observations over the same regions as in Fig. 3. The figure demonstrates that the interannual variability is reasonably well reproduced in ECHAM5. Large systematic biases are not found in any season for either Eurasia or North America. This is in contrast to Frei et al. (2003), who found a general underestimation of the interannual variability in the majority of the 15 AMIP II models under investigation. To compare the interannual variability between ECHAM5 and NOAA, the range between the first and third quartile, containing $50 \%$ of the entire sample, was computed for both NOAA and ECHAM5 on a seasonal basis. For Eurasia, ECHAM5 simulated 133\% [winter (DJF)], 98\% [spring (MAM)], and 84\% [autumn $(\mathrm{SON})]$ of the observed range. Corresponding values for North America are $112 \%, 73 \%$, and $75 \%$ for DJF, MAM, and SON, respectively. In winter, the model seems to overestimate the observed interannual variations, while in the two shoulder seasons, variations are too low. Similar results are generally found for subcontinental regions, although the scatter in SCA increases with decreasing land area.

\section{3) TREndS}

Several studies report a significant decrease in hemispheric SCA during the last three decades (Brown 2000; Dye 2002). Based on the monthly gridded NOAA snow cover data for the time interval 1979-99, significant negative trends in the SCF were computed for the Northern Hemispheric spring (Figs. 6a,c). Data before
1979 were ignored because of an inhomogeneity caused by launching the Advanced Very High Resolution Radiometer (AVHRR) in November 1978. Figures 6a and $6 \mathrm{c}$ reveal that SCF depletion is most pronounced in regions where the snow deck is relatively shallow and the potential snow albedo feedback is large. Over Eurasia and North America, the spring (March-May) SCA decreased by $-7.8 \times 10^{5}$ and $-1.9 \times 10^{5} \mathrm{~km}^{2}(10 \mathrm{yr})^{-1}$ respectively. These values agree well with results in Brown (2000) who investigated trends in the SCA from 1915-97. A highly statistically significant reduction in the SCA has occurred in large parts of Europe in February-March, often exceeding 10\% during the last two decades of the twentieth century.

Comparing the NOAA trends with the ECHAM5 simulation (Figs. 6b,d) reveals that negative trends are also generally found in the model simulation. This is probably related to the simulated positive temperature trend that is primarily driven by the prescribed SST and sea ice coverage. However, regional differences are significant, and they are further enhanced by a different position of the snow line in the observation and simulation.

\section{c. Error analysis}

This section investigates the expected error due to inhomogeneities in the time series, trends, and different temporal resolution of the source data. Previous studies on snow cover frequently ignore these problems. Thus, a detailed discussion will be included here.

\section{1) TRENDS}

Trends in snow cover are not only of interest for detection studies on anthropogenic climate change but are also responsible for sampling errors when comparing climatologies that are derived from data records covering different time intervals. To illustrate this further, 5-yr European SCA climatologies for the time periods 1979-83 and 1995-99 were computed from NOAA data. The February mean for the first interval was $16 \%$ (February) and 26\% (March) higher than the mean for the more recent 5-yr period. The comparison of SCA climatologies from different time periods may therefore be inaccurate because of trends in the data.

Repeating the investigations with detrended data has, however, demonstrated that the conclusions drawn from Fig. 3 for subcontinental and hemispheric scales remain correct as the averaging periods of the climatologies do not significantly differ and often overlap. Only the results from MODIS should be used with caution because the corresponding time period is short and 
a) $\mathrm{NH}$, land, without Greenland [>20N]
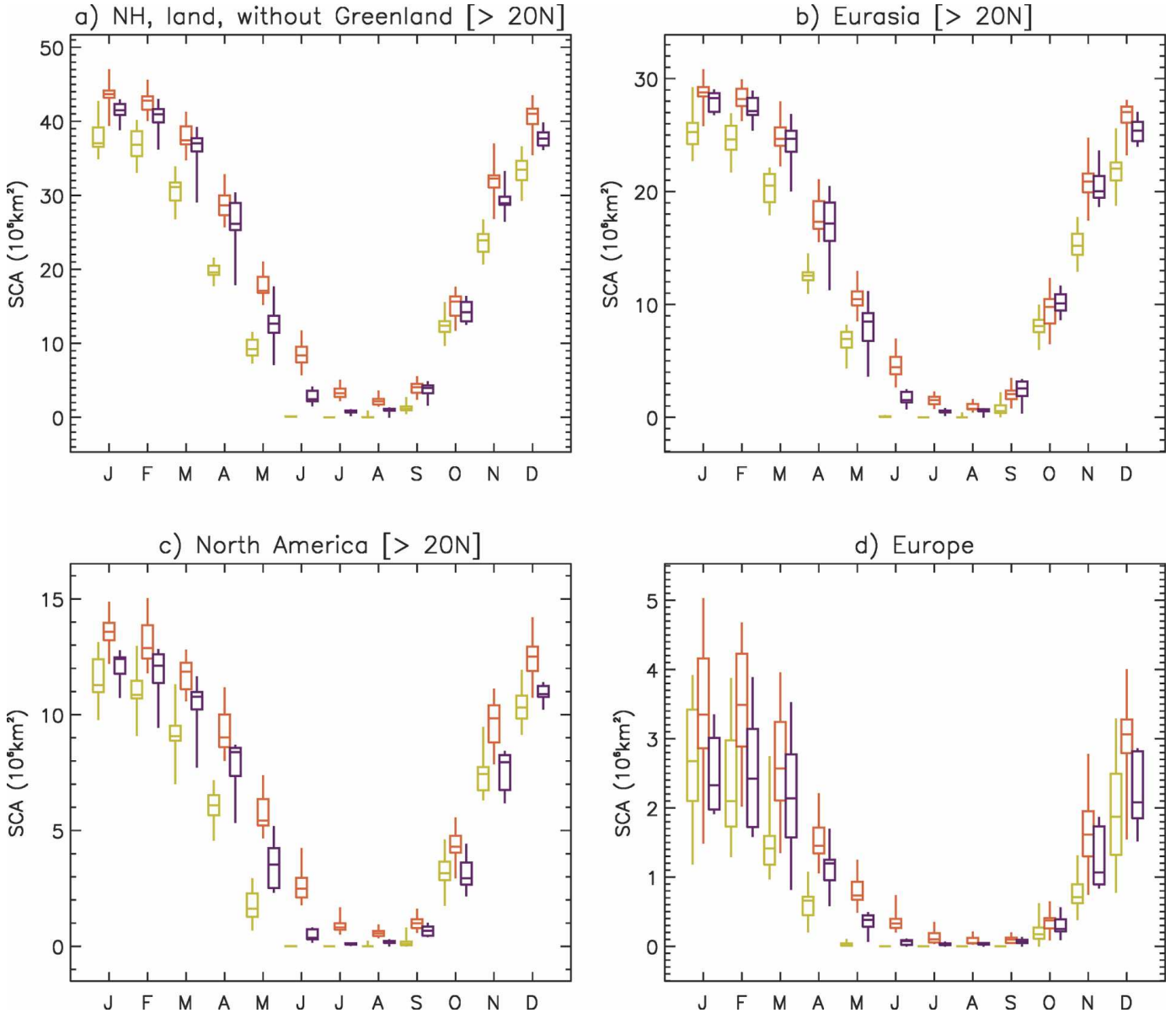

FIG. 5. Variations in observed (NOAA and SSM/I) and modeled (ECHAM5) SCAs for all months. Ranges of SCAs are indicated by the box and whiskers: the middle line of the box is the median value; the top and bottom of the box are the third and first quartiles, respectively; whiskers indicate minimum and maximum values. Each month is represented by three boxes: From left to right: green: ECHAM5 (1979-99); red: NOAA (1979-99); blue: SSM/I (1987-98). (a) Northern Hemisphere without Greenland; (b) as (a) but for Eurasia $\left(>20^{\circ} \mathrm{N}\right)$; (c) as (a) but for North America $\left(>20^{\circ} \mathrm{N}\right)$; (d) as (a) but for Europe $\left(<35^{\circ} \mathrm{E}\right)$.

has a limited overlap with the averaging periods of the other datasets that are used in this study.

\section{2) INHOMOGENEITIES}

Quantitative analyses, such as the computation of trends and mean values, are often hampered by inhomogeneities in the data. These inhomogeneities may be caused by either changes in instrumentation, by poorly maintained equipment, or (for in situ measurements) by displacement of the measuring devices. Inhomogeneities in long time series may generate serious errors in both the climatologies and trends.

Figure 7 displays the monthly SCA time series of all remote-sensed and simulated datasets used in this study averaged over Eurasia, North America, and the Northern Hemisphere. By subtracting the mean annual SCA cycle from all data records, inhomogeneities can easily be detected by visual inspection. Figure 7 clearly reveals the change in the mean and variability in November 1978 due to the replacement of the Very High Resolution Radiometer (VHRR) by the Advanced Very High Resolution Radiometer (AVHRR) in November 1978. Averaging NOAA data over North America in the time intervals 1974-77 (VHRR) and 1979-82 (AVHRR) reveals increases in the DJF and MAM SCA mean of $7.5 \%$ (or $1.03 \times 10^{6} \mathrm{~km}^{2}$ ) and $15.5 \%$ (or $1.54 \times 10^{6} \mathrm{~km}^{2}$ ), respectively. This apparent increase is clearly in contrast to the findings derived from homogeneous data that show a pronounced decrease in the SCA in the 1970s and 1980s (Brown 2000). Inspecting the NOAA data more rigorously, for example, by computing cumulative sums of the data record and checking the curve for changes in the slope, also reveals the second discontinuity in the NOAA data 
a) NOAA, FEB \& MAR

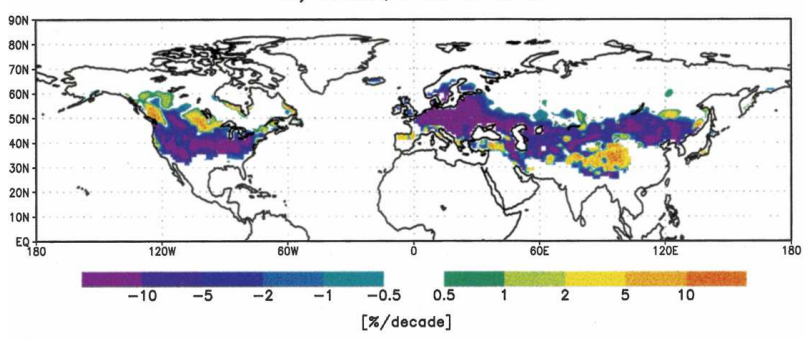

b) ECHAM5, FEB \& MAR

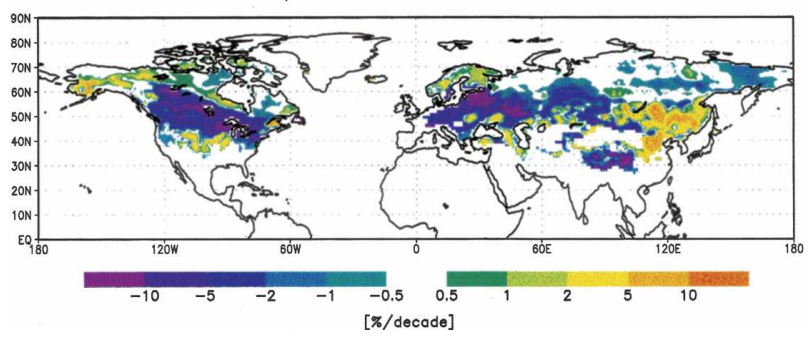

c) NOAA, APR \& MAY

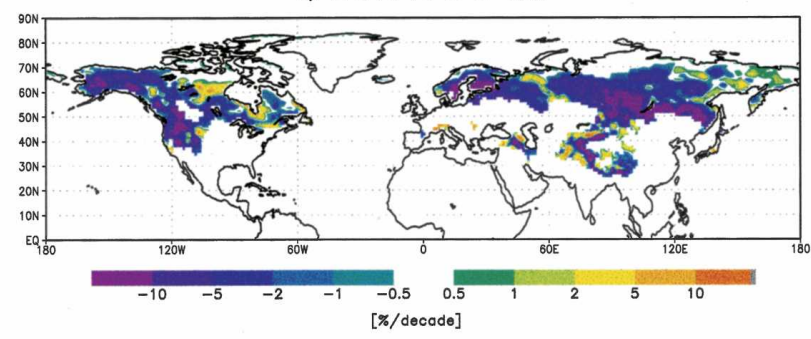

d) ECHAM5, APR \& MAY

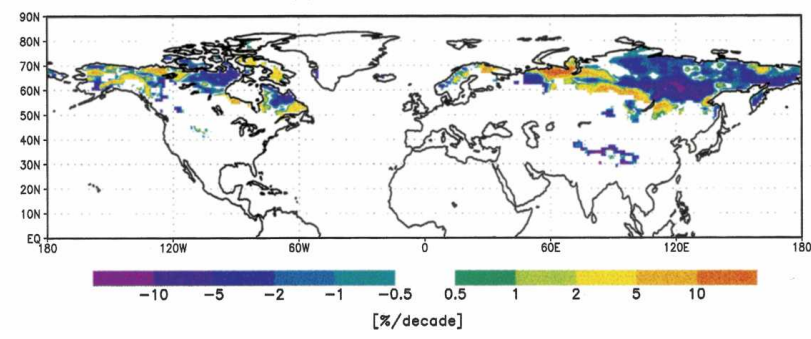

FIG. 6. Decadal trends in SCF between $0^{\circ}$ and $90^{\circ}$ N. (left) Feb-Mar 1979-99. (right) Apr- May 1979-99. (a), (c) NOAA; (b), (d) ECHAM5. Trends are given as $\%$ decade $^{-1}$.

record in 1972 when the VHRR was launched. It can easily be verified by computing cumulative sums of the data records that are used in this study that no relevant discontinuities are found in the data other than the NOAA snow cover record.

In summary, analyses based on inhomogeneous data, such as the discontinuities found in the NOAA snow data record, may easily lead to incorrect conclusions and fictitious trends. It is thus fundamental to test data for their homogeneity before they are used in validation studies. For the above reasons, NOAA SCF data were only used after 1978.

\section{3) Temporal Resolution}

The temporal resolution of all remote-sensed and ground-based observational data that are used in this study is one month. To not mismatch data of different temporal resolution, the computation of SCF and SD from SWE was carried out on a monthly basis as well, although finer temporal resolution is available from the model. In the following, some reasoning is given as to why the use of a consistent temporal resolution is important. This is done by investigating the difference between monthly SCF derived from either 6-hourly or monthly simulated SWE. The monthly SCFs were derived using two different methods. As a first approach, hereafter called MET1, 6-hourly SCF is computed according to Eq. (1), with a subsequent calculation of monthly SCF through the averaging of the 6-hourly SCF. The second method (MET2), used in most studies (and in this study as well), computes monthly SCF from monthly SWE, again using Eq. (1). To illustrate the differences between this two averaging methods, the SCF for the two following cases with the same monthly SWE has been computed: SWE is equal to (i) $1 \mathrm{~cm}$ on all 30 days or (ii) $10 \mathrm{~cm}$ snow on the first 3 days with the remaining 27 days snow-free. While the first method provides monthly mean SCFs of 0.72 and 0.095 [Eq. (1), flat land] for case i and case ii, respectively, MET2 results in SCF $=0.72$ for both cases. Similar results, albeit less pronounced, are found in Fig. 8, which shows a decrease in SCF when using MET1 instead of MET2. Figures $8 \mathrm{a}-\mathrm{d}$ clearly show that the effect is most pronounced in areas close to the snow line, with frequent melting and/or shallow snowpacks. The evaluation suggests that monthly SCF would be systematically lower in areas with fractional snow cover when using MET1 instead of MET2.

\section{Results and discussion: Surface albedo}

\section{a. Annual cycles}

In this section, simulated surface albedos are compared with the remote-sensed PINKER and MODIS climatologies. Since the ECHAM models do not distinguish between the visible and near-infrared surface albedo, the discussion will be limited to broadband albedos.

Figure 9 demonstrates that positive biases of simulated surface albedo occur during the snow season, 


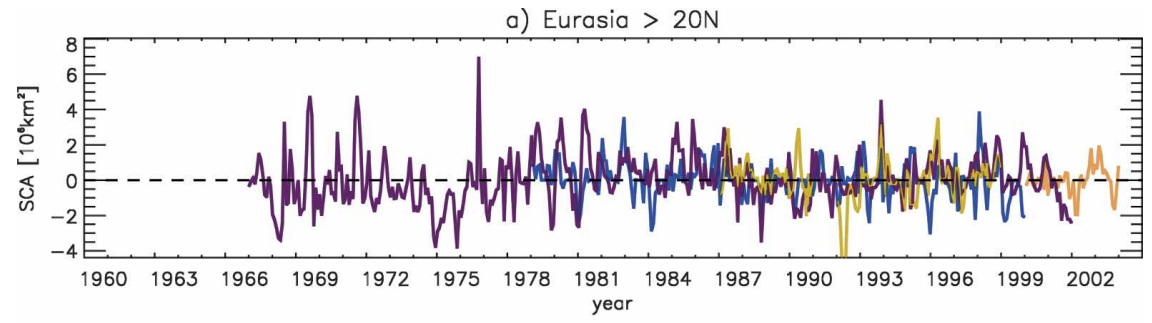

b) North America $>20 \mathrm{~N}$

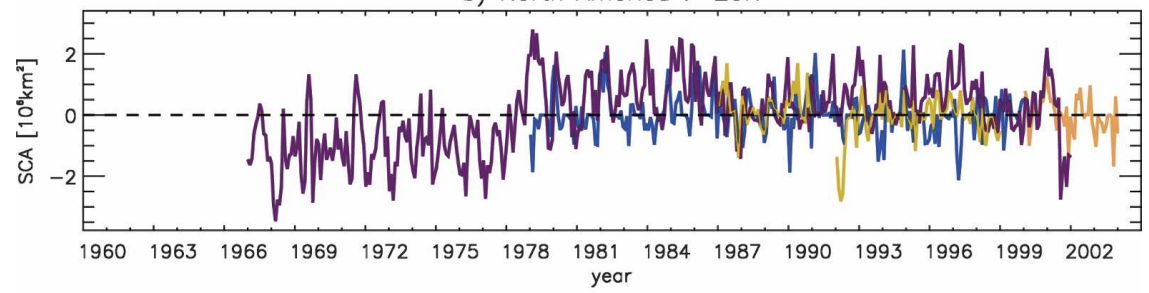

c) Northern Hemispheric land, excluding greenland

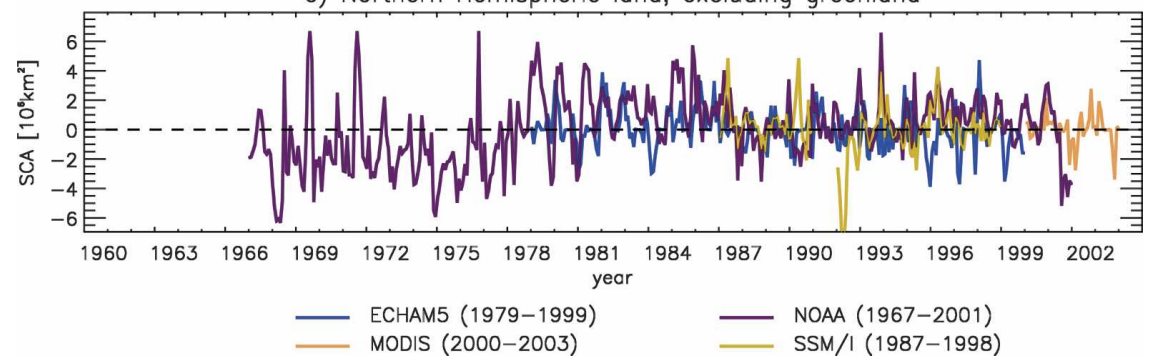

FIG. 7. Time series of SCA with the mean annual cycles removed. Monthly time series are shown for ECHAM5-T106 (1979-99), NOAA (1966-2001), SSM/I (1987-98), and MODIS (2000-03).

whereas in snow-free months the simulated land albedos agree quite well with observed data. Whereas ECHAM5 is lower than ECHAM4 over the Himalayas/ Tibetan Plateau (Fig. 9b), the opposite is found over the boreal forests (Fig. 9a). ECHAM5 is closer to observations in the Himalayan area and worse than ECHAM4 over the boreal forests. This is somewhat surprising, as Roesch et al. (2001) report that the albedo of snow-covered forests was significantly reduced in ECHAM5 in order to be in line with results from field campaigns. The reason for this discrepancy is given in section $5 \mathrm{~b}$. The lower Himalayan albedo in ECHAM5 is caused by reducing the SCF to account for the effects of subgrid variability of topography [see Eq. (1)].

In snow-free regions, simulated and observed surface albedos are generally in good agreement. Compared to the MODIS and PINKER product, the ECHAM models are slightly too low over the Amazonian rain forest (Fig. 9d) but do not show any systematic biases over bright sand deserts such as the Sahara (Fig. 9c).

In summary, both ECHAM4 and ECHAM5 capture snow-free surface albedos quite well, whereas a sub- stantial overestimation is found for boreal forests when snow is present.

\section{b. Deficiencies in the ECHAM5 albedo parameterization}

The aim of this section is to identify and address possible deficiencies in the ECHAM5 surface albedo parameterization based on previous results in this analysis. A significant overestimation of the surface albedo over snow-covered forests in ECHAM5 was found, as described in the previous section. Figure 10a shows that the albedo over snow-covered Taiga forests is generally higher in ECHAM5 than in ECHAM4. This is most evident over the eastern part of Siberia. This deficiency can be mainly attributed to new surface boundary conditions compiled by Hagemann (2002). Whereas the LAI in ECHAM4 does not vary with time, an annual LAI cycle is prescribed in ECHAM5. Comparing the differences in the surface albedo (Fig. 10a) and the LAI (Fig. 10b) reveals that similar patterns, but of opposite sign, are found, suggesting smaller snow masking by the canopy in ECHAM5.

To illustrate the albedo differences caused by differ- 

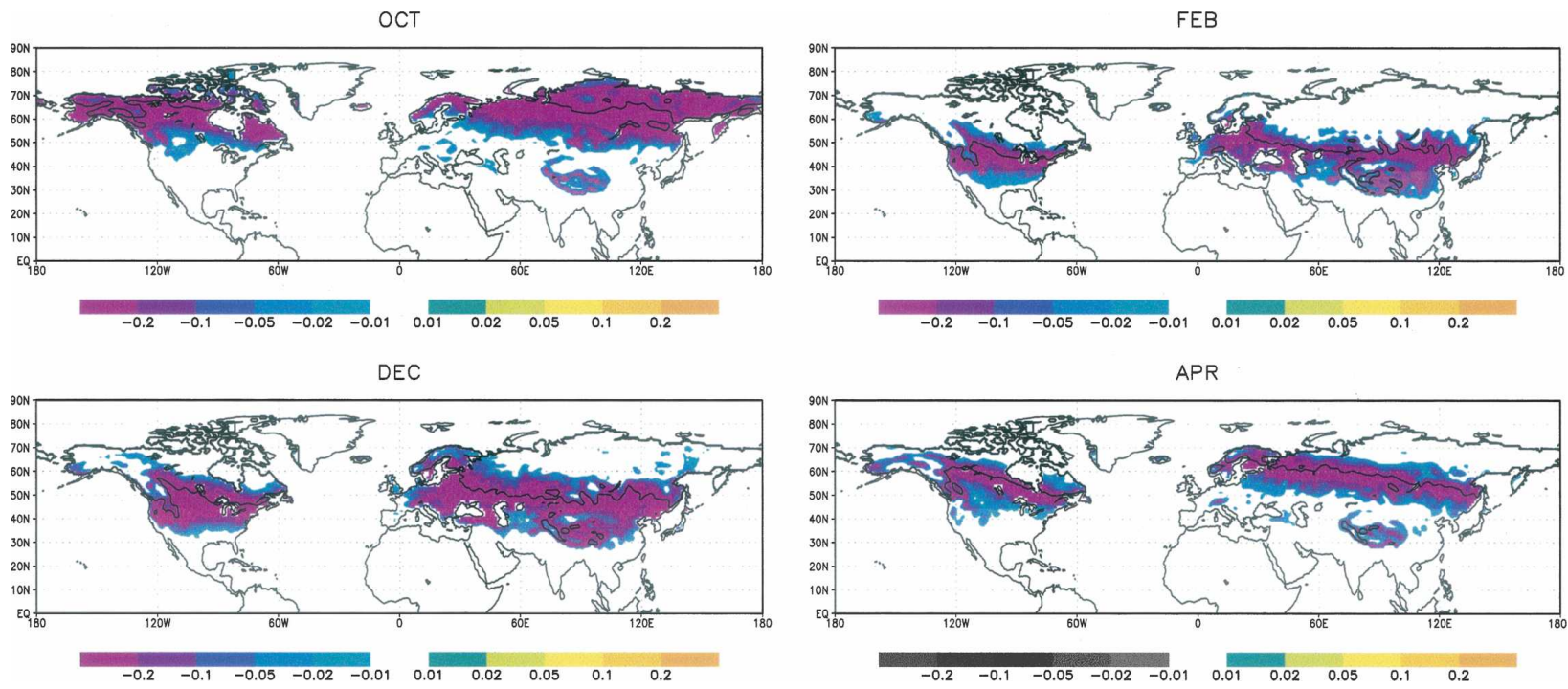

FIG. 8. Monthly climatologies of SCF, difference MET1-MET2 [cf. section 4.c(3)] derived from 6-hourly (MET1) and monthly (MET2) snow water equivalent from the 20-yr ECHAM5 (T106L31) simulation. Computation of SCF from SWE according to Eq. (1). The snow line $(50 \% \mathrm{SCF})$ is shown as a thick solid line.

ent LAIs in deciduous Taiga forests, the total surface albedo is computed for LAI $=3$ (a typical value in ECHAM4) and for LAI $=0.3$ (a typical value in ECHAM5 during the dormancy season). Inserting the above values into Eq. (3) leads to sky view factors of
0.74 and 0.05 , respectively. The total surface albedo is then calculated using Eq. (2) and assuming (i) a closed snow cover, (ii) a forest fraction of $100 \%$, (iii) a maximal snow storage on the trees, and (iv) albedos of 0.2 and 0.8 for snow-covered forests and pure snow, respec-
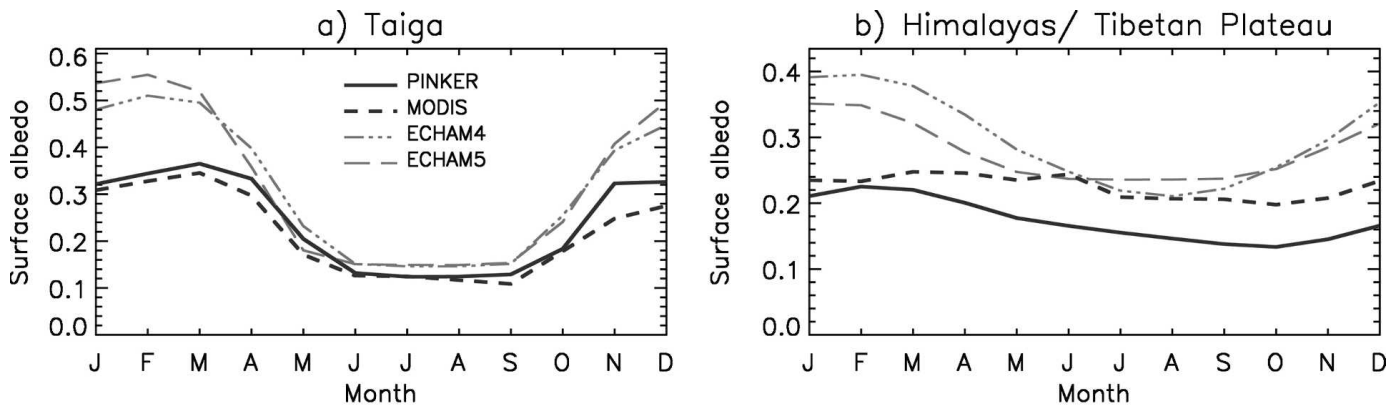

c) Sahara desert
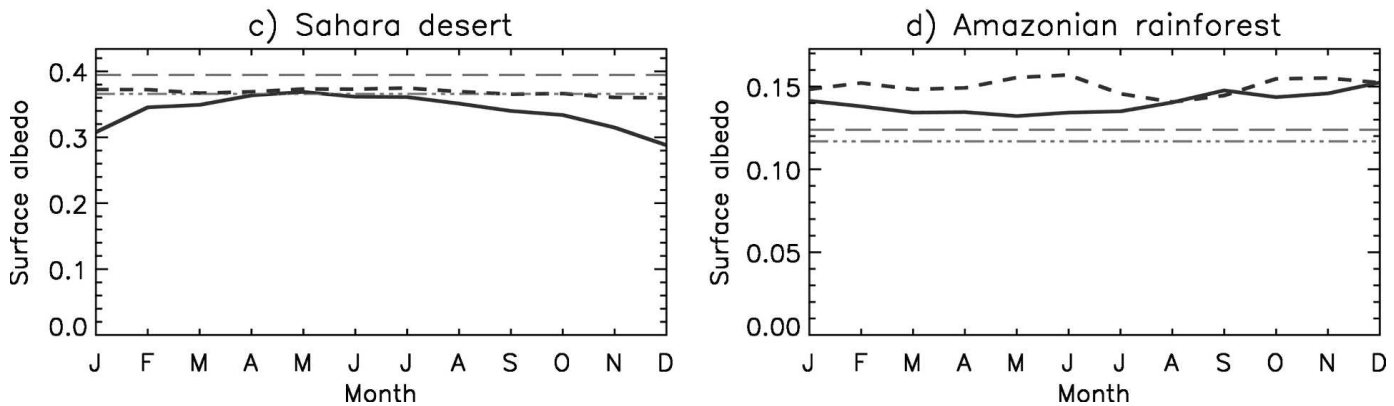

FIG. 9. Annual cycles of broadband surface albedos as simulated for ECHAM4, ECHAM5, and the PINKER and MODIS climatologies (cf. section 3b). MODIS albedos are computed from the mean between white-sky (direct beam) and diffuse-sky albedos, weighted by the diffuse and direct radiation, respectively. The diffuse ratio has been estimated from ISCCP D2 data according to Roesch et al. (2004). Only latitudes south of the polar night are included in order to allow for a fair comparison between model and visible imagery data (MODIS and PINKER). 
a) Surface albedo

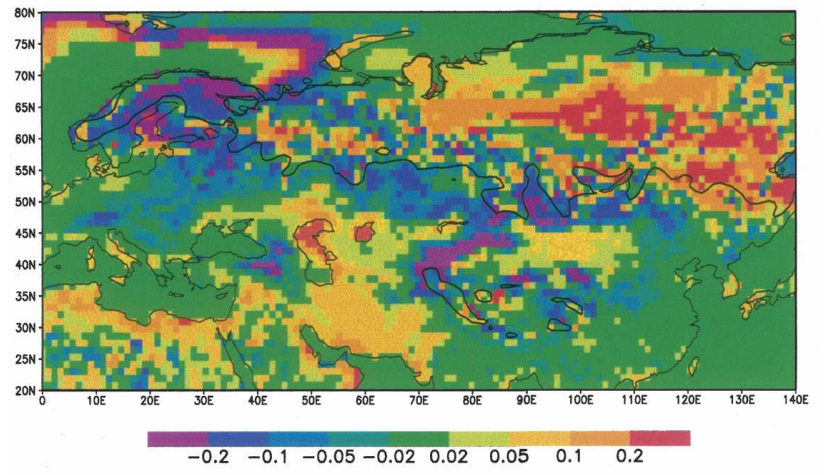

c) SCF

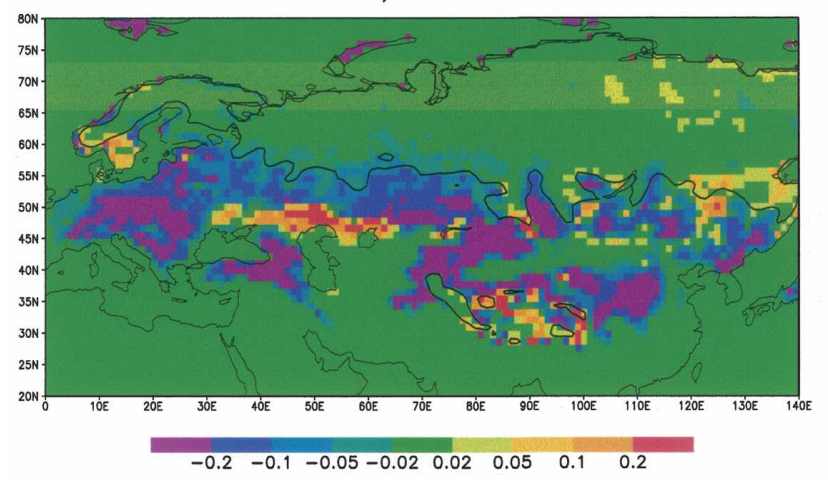

b) LAl

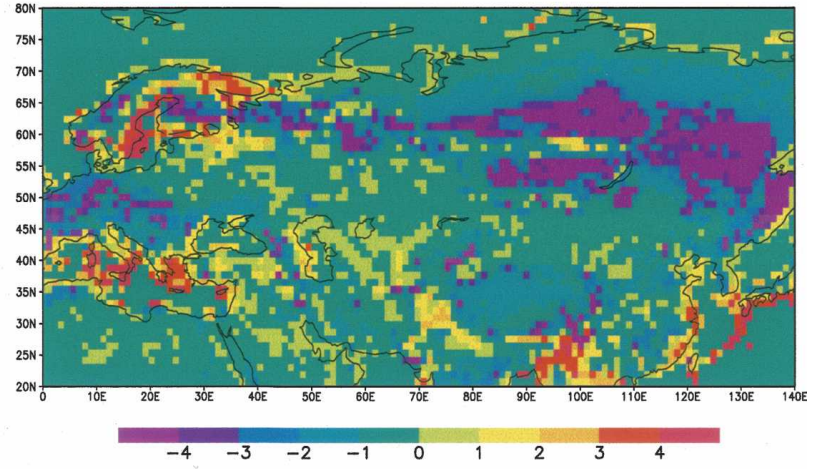

d) Forest fraction

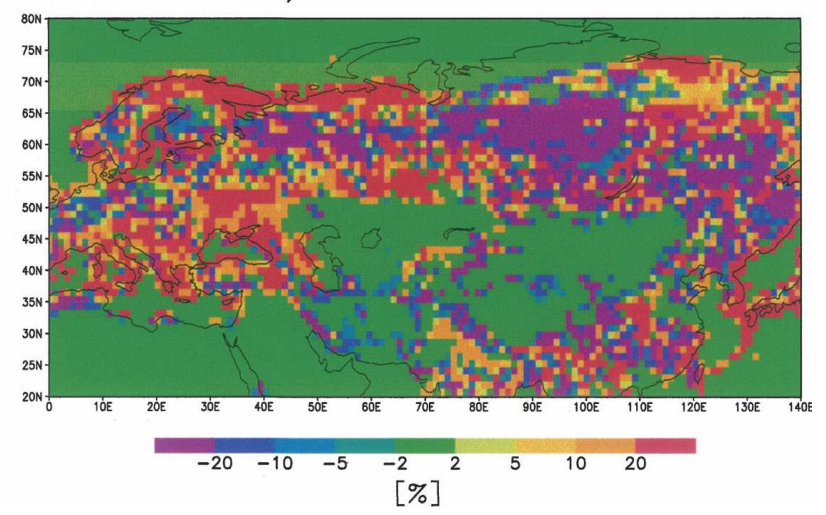

FIG. 10. Differences between ECHAM5 and ECHAM4 for the region $20^{\circ}-90^{\circ} \mathrm{N}$ in March. (a) Surface albedo; (b) LAI; (c) SCF [derived from monthly snow water equivalent according to Eq. (1)]; (d) forest fraction. Solid thick lines in (a) and (c) indicate the snow line simulated by ECHAM5 ( $\mathrm{SCF}=50 \%)$.

tively. This leads to total surface albedos of 0.23 and 0.64 when retrieving the LAI from ECHAM4 and ECHAM5, respectively.

Using low LAI values during the dormancy season for deciduous needleleaf trees is justifiable in the evaporation parameterization. In the SCF parameterization as given in Eqs. (1)-(7), however, the LAI should be replaced by the sum of LAI and stem area index (SAI), where SAI has been set to 2 for all forest types in the Biosphere-Atmosphere Transfer Scheme (Dickinson et al. 1993). It seems reasonable to use the SAI when trees have lost their needles or leaves in order to mimic the stem and branches shadowing the ground below the canopy. For fully leaved trees, no correction is necessary as the foliage obscures the tree's stems and branches. Considering this modification $(\mathrm{SAI}=2)$ would reduce the total surface albedo in the example above from 0.64 to a more realistic albedo of 0.26 for a "typical" snow-covered boreal forest in eastern Siberia. Further improvements could be achieved by providing separate LAIs for the forest and forestfree fraction within GCM grid cells.

A small contribution to higher albedo values of snow-covered boreal forest in ECHAM5 compared to ECHAM4 is caused by generally lower forest fractions (Fig. 10d). In Scandinavia, however, the modification in the forest mask seems to play the major role where distinctly higher forest fractions cause darker surfaces (the LAI remains relatively high for needleleaf evergreen forests, which avoids excessively high sky view factors).

In March, ECHAM5 simulates distinctly lower surface albedos south of the SCF $=50 \%$ snow line when compared to ECHAM4 (Fig. 10a). This is mainly due to lower SCFs in these areas (Fig. 10b), which is again related to earlier snowmelt in ECHAM5. It should be emphasized that significant changes in the SCF only require small changes in SWE for shallow snowpacks since diagnostic SCF is very sensitive to changes in SWE below an SD of approximately $10 \mathrm{~cm}$ (Fig. 4).

Further improvements are feasible with regard to the snow albedo at the freezing point. The melting snow albedo has been set to 0.3 in ECHAM5 (Roeckner et al. 2003). Ground-based measurements of surface albedo, however, show that this value is probably too low (Roesch et al. 1999; Aoki et al. 2003). 


\section{Conclusions and outlook}

Surface albedo has long been recognized as one of the key surface parameters in climate models through its direct effect on the energy balance. Nevertheless, the parameterization of surface albedo, which is closely linked to diagnostic SCF in snow-covered areas, is still oversimplified in most GCMs, for example, ignoring the dependence on wavelengths, incidence angle of incoming solar radiation, or soil moisture. This study presents a comparison of simulated snow cover (in terms of SD, SCF, SCA) and the surface albedo with remotesensed and ground-based observations.

The annual cycle of SD simulated by ECHAM5 agrees well with ground-based observations in North America and Eurasia, whereas ECHAM4 produces excessive SD in late winter and spring, along with a delayed snowmelt. It is shown that both ECHAM4 and ECHAM5 capture the annual cycle of the SCA at a hemispheric and continental scale with reasonable accuracy. Compared to NOAA retrievals, ECHAM5 tends to underestimate the SCF mainly in North America. ECHAM4 agrees well with SSM/I and MODIS data in North America, whereas Eurasian SCA is probably too high in spring, consistent with the excessive SD. The observed trend in SCA during the last two decades of the twentieth century is reasonably well reproduced in the ECHAM5 simulation.

An error analysis demonstrated that wrong conclusions might be drawn when ignoring discontinuities due to changes in the instrumentation and trends in the observed data records. Further, it was shown that simulated monthly SCFs are sensitive to the choice of the temporal resolution of SWE (6-hourly versus monthly) used for the conversion.

Simulated surface albedos were compared with PINKER and MODIS climatologies. ECHAM5 is in better agreement with observations in the HimalayanTibeten area than ECHAM4. In contrast, the positive surface albedo bias over boreal forests in winter and spring in ECHAM4 is more pronounced in ECHAM5. This deficiency is primarily due to ignoring the snowmasking effect of stems and branches after the trees have lost their needles. To keep the current surface albedo parameterization, it is suggested to include the stem area index in the parameterization of the sky view factor for deciduous needleleaf trees.

Acknowledgments. The research reported herein was performed at the Swiss Federal Institute of Technology, Institute for Climate Research, under the sponsorship of NCCR Climate.
REFERENCES

Aoki, T., A. Hachikubo, and M. Hori, 2003: Effects of snow physical parameters on shortwave broadband albedos. J. Geophys. Res., 108, 4616, doi:10.1029/2003JD003506.

Armstrong, R., and M. Brodzik, 2002: Hemispheric-scale comparison and evaluation of passive microwave snow algorithms. Ann. Glaciol., 34, 38-44.

Barnett, T., L. Dümenil, U. Schlese, E. Roeckner, and M. Latif, 1989: The effect of Eurasian snow cover on regional and global climate variations. J. Atmos. Sci., 46, 661-685.

Briegleb, B., and V. Ramanathan, 1982: Spectral and diurnal variations in clear sky planetary albedo. J. Appl. Meteor., 21, 1160-1171.

Brown, R., 2000: Northern Hemisphere snow cover variability and change. J. Climate, 13, 2339-2355.

Chang, A., J. Foster, and D. Hall, 1987: Nimbus-7 SMMR derived global snow cover parameters. Ann. Glaciol., 9, 39-44.

Charney, J., W. Quirk, S. Chow, and J. Kornfield, 1977: A comparative study of the effects of albedo change on drought in semi-arid regions. J. Atmos. Sci., 34, 1366-1385.

Claussen, M., 1997: Modeling bio-geophysical feedbacks in the African and Indian monsoon region. Climate Dyn., 13, 247 257.

Colton, M., and G. Poe, 1999: Intersensor calibration of DMSP SSM/I's: F-8 to F14, 1987-1997. IEEE Trans. Geosci. Remote Sens., 37, 418-439.

Culf, A., G. Fisch, and M. Hodnett, 1995: The albedo of Amazonian forest and range land. J. Climate, 8, 1544-1554.

Dickinson, R., A. Henderson-Sellers, and P. Kennedy, 1993: Biosphere-Atmosphere Transfer Scheme (BATS) Version 1e as coupled to the NCAR Community Climate Model. NCAR Tech. Note NCAR/TN-387+STR, 72 pp.

Douville, H., J.-F. Royer, and J.-F. Mahfouf, 1995: A new snow parameterization for the Météo-France climate model, Part 2: Validation in a 3-D GCM experiment. Climate Dyn., 12, $37-52$.

- F. Chauvin, S. Planton, J. Royer, D. Salas-Melia, and S. Tyteca, 2002: Sensitivity of the hydrological cycle to increasing amounts of greenhouse gases and aerosols. Climate Dyn., 20, 45-68.

Dye, D., 2002: Variability and trends in the annual snow cover cycle in Northern Hemisphere land areas, 1972-2000. Hydrol. Processes, 16, 3065-3077.

Edelmann, W., D. Majewski, E. Heise, P. Prohl, G. Doms, B. Ritter, M. Gertz, and T. Hanisch, 1995: Dokumentation des EM/DM-Systems. Deutscher Wetterdienst Tech. Rep., 550 pp. [Available from Deutscher Wetterdienst, Zentralamt, D-63004 Offenbach am Main, Germany.]

Foster, D., and R. Davy, 1988: Global snow depth climatology. USAF Publ. USAFETAC/TN-88/006, Scott Air Force Base, Illinois, $48 \mathrm{pp}$.

Foster, J., and Coauthors, 1996: Snow cover and snow mass intercomparison of general circulation models and remotely sensed datasets. J. Climate, 9, 409-426.

Frei, A., J. Miller, and D. Robinson, 2003: Improved simulations of snow extent in the second phase of the Atmospheric Model Intercomparison Project (AMIP-2). J. Geophys. Res., 108, 4369, doi:10.1029/2002JD003030.

Gates, W. L., 1992: AMIP: The Atmospheric Model Intercomparison Project. Bull. Amer. Meteor. Soc., 73, 1962-1970.

Groisman, P., R. Knight, T. Karl, D. Easterling, B. Sun, and J. Lawrimore, 2004: Contemporary changes of the hydrological 
cycle over the contiguous United States: Trends derived from in situ observations. J. Hydrometeor., 5, 64-85.

Gutzler, D., and R. Rosen, 1992: Interannual variability of wintertime snow cover across the Northern Hemisphere. J. Climate, 5, 1441-1447.

Hagemann, S., 2002: An improved land surface parameter dataset for global and regional climate models. Max Planck Institute for Meteorology Rep. 336, 21 pp.

— , K. Arpe, and E. Roeckner, 2006: Evaluation of the hydrological cycle in the ECHAM5 model. J. Climate, 19, 38103827.

Henderson-Sellers, A., and M. Wilson, 1983: Surface albedo data for climate modeling. Rev. Geophys. Space Phys., 21, 17431778.

Huffman, G., and Coauthors, 1997: The Global Precipitation Climatology Project (GPCP) Combined Precipitation Dataset. Bull. Amer. Meteor. Soc., 78, 5-20.

Iwasaki, T., 1991: Year-to-year variation of snow cover area in the Northern Hemisphere. J. Meteor. Soc. Japan, 69, 209-217.

Kukla, G., and D. Robinson, 1981: Accuracy of snow and ice monitoring. Snow Watch 1980, Glaciological Data, Rep. GD5, 91-97.

Marshall, S., J. Roads, and G. Glatzmaier, 1994: Snow hydrology in a general circulation model. J. Climate, 7, 1251-1269.

Masuda, K., Y. Morinaga, A. Numaguti, and A. Abe-ouchi, 1993: The annual cycle of snow cover extent over the Northern Hemisphere as revealed by NOAA/NESDIS satellite data. Geogr. Rep. Tokyo Metropol. Univ., 28, 113-132.

New, M., M. Hulme, and P. Jones, 2000: Representing twentiethcentury space-time climate variability. Part II: Development of 1901-96 monthly grids of terrestrial surface climate. J. Climate, 13, 2217-2238.

Pinker, R., 1985: Determination of surface albedo from satellites. Adv. Space Res., 5, 333-343.

_ _ and I. Laszlo, 1992: Modeling of surface solar irradiance for satellite applications on a global scale. J. Appl. Meteor., 31, 194-211.

Potter, G., H. Elsasser, M. MacCracken, and J. Ellis, 1981: Albedo change by man: Test of climatic effects. Nature, 291, 47-50.

Randall, D., and Coauthors, 1994: Analysis of snow feedbacks in 14 general circulation models. J. Geophys. Res., 99, $20757-$ 20771.

Robinson, D., 1993: Monitoring Northern Hemisphere snow cover. Snow Watch '92, Glaciological Data, Rep. GD-25, $1-25$.

$\longrightarrow$ K. Dewey, and R. Heim, 1993: Global snow cover monitoring: An update. Bull. Amer. Meteor. Soc., 74, 1689-1696.

Robock, A., K. Vinnikov, C. Schlosser, N. Speranskaya, and Y. Yue, 1995: Use of midlatitude soil moisture and meteorological observations to validate soil moisture simulations with biosphere and bucket models. J. Climate, 8, 15-35.
Roeckner, E., and Coauthors, 1992: Simulation of the present day climate with the ECHAM model: Impact of model physics and resolution. Max Planck Institute for Meteorology Rep. 93, $171 \mathrm{pp}$.

- and Coauthors, 1996: The atmospheric general circulation model ECHAM-4: Model description and simulation of present day climate. Max Planck Institute for Meteorology Rep. 218, 90 pp

— and Coauthors, 2003: The atmospheric general circulation model ECHAM5: Part I. Max Planck Institute for Meteorology Rep. 349, 127 pp.

Roesch, A., 2000: Assessment of the land surface scheme in climate models with focus on surface albedo and snow cover. Zürcher Klima-Schriften 78, ETH Zurich, 242 pp.

—, H. Gilgen, M. Wild, and A. Ohmura, 1999: Assessment of GCM simulated snow albedo using direct observations. Climate Dyn., 15, 405-418.

—, M. Wild, H. Gilgen, and A. Ohmura, 2001: A new snow cover fraction parameterization for the ECHAM4 GCM. Climate Dyn., 17, 933-946.

, R. Pinker, and A. Ohmura, 2002: Comparison of spectral surface albedo and their impact on the general circulation model simulated surface climate. J. Geophys. Res., 107, 4221, doi:10.1029/2001JD000809.

_ C. Schaaf, and F. Gao, 2004: Use of Moderate-Resolution Imaging Spectroradiometer bidirectional reflectance distribution function products to enhance simulated surface albedos. J. Geophys. Res., 109, D12105, doi:10.1029/2004JD004552.

Schaaf, C., and Coauthors, 2002: First operational BRDF, albedo and nadir reflectance products from MODIS. Remote Sens. Environ., 83, 135-148.

Sellers, P., and Coauthors, 1996: A revised land surface parameterization ( $\mathrm{SiB} 2)$ for atmospheric GCMs. Part I: Model formulation. J. Climate, 9, 676-705.

Verseghy, D., 1991: CLASS-A Canadian Land Surface Scheme for GCMs. I: Soil model. Int. J. Climatol., 13, 111-133.

_ , N. McFarlane, and M. Lazare, 1993: CLASS_A Canadian Land Surface Scheme for GCMs. II: Vegetation model and coupled runs. Int. J. Climatol., 13, 347-370.

Walsh, J., and B. Ross, 1988: Sensitivity of 30-day dynamical forecasts to continental snow cover. J. Climate, 1, 739-754.

Wiesnet, D., C. Ropelewski, G. Kukla, and D. Robinson, 1987: A discussion of the accuracy of NOAA satellite-derived global seasonal snow cover measurements. Proc. Vancouver Symp.: Large Scale Effects of Seasonal Snow Cover, Vancouver, BC, Canada, IAHS Publ. 166, 291-304.

Yang, Z.-L., R. Dickinson, A. Robock, and K. Vinnikov, 1997: Validation of the snow submodel of the BiosphereAtmosphere Transfer Scheme with Russian snow cover and meteorological observational data. J. Climate, 10, 353-373. 